\title{
Quantitative evaluation of flexibility in undergraduate engineering curricula in the United Arab Emirates
}

\author{
Naif A. Darwish ${ }^{1 *}$ \& Muhammad Qasim ${ }^{1}$ \\ ${ }^{1}$ American University of Sharjah, $U A E$
}

\begin{abstract}
In academia, smooth progression of students significantly depends on the way curricula are developed and organized. Curricula or study plans with high degree of interconnectivity between courses, multiple prerequisites, and hierarchically structured courses tend to complicate the smooth progress of the enrolled students. In this work, a rigorous quantitative relaxation indicator, developed and published elsewhere by the first author, has been applied to quantify the degree of stiffness and rigidity in undergraduate engineering curricula at the American University of Sharjah (AUS), the University of Sharjah (UOS), United Arab Emirates University (UAEU), and the Petroleum Institute (PI), which are the leading universities in the United Arab Emirates. Results indicate high rigidity (low relaxation indices) due to high degree of interconnectivity between courses, specifically in the second year of the study plans. The chemical engineering curriculum at PI exhibited the least flexibility due to very strong pre-and-co-requisite ties while the civil \& environmental curriculum at UAEU showed the highest flexibility. The curricula considered require immediate attention and reorganization in order to facilitate smooth sequential progress of the students from one semester to another. A list of courses that require relaxation of strong pre-and corequisites ties has been presented for each curriculum.
\end{abstract}

\author{
Keywords \\ study plan \\ curriculum \\ pre-requisites \\ co-requisites \\ curriculum organization
}

\section{INTRODUCTION}

In order to obtain a higher education degree, university or college students are required to pass all the courses within their respective study plan or curriculum. In higher education, procrastination and time investment have become important concerns in the study of student performance and academic progress. A considerable proportion of research on student performance and academic progress has focused on individual differences between the students in terms of time management and procrastination (Hulst \& Jansen, 2002). The relationship between procrastination and academic performance has been studied and discussed extensively in literature (Schouwenburg, 1992; Johnson \& Bloom, 1995; Macan, 1994; Nonis, et al., 1998; Milgram, et al., 1992; Milgram, et al., 1995; Senécal, et al., 1995). However, in recent years, academic researchers have highlighted that academic performance does not solely depend on the student characteristics but also depends on the organization of the curriculum. In fact, institutes in higher education may improve students' progress and reduce procrastination by efficient curriculum structure (Hulst \& Jansen, 2002; Darwish, 2011). Study progress has been shown to be affected by many curriculum-related factors. According to Crombag et al. (1975), students adjust their study behavior to the way the curriculum or study plan is organized. Other studies considered the effect of the academic calendar on the study progress of the students (Vaughan \& Carlson, 1992; Jansen, 1993). It was observed that the study progress is slower in two- or three-

\footnotetext{
${ }^{*}$ Correspondence to: ndarwish@aus.edu
} 
semester periods than in study programs that involve six periods of seven weeks. Hulst \& Jansen (2002) also studied effect of curriculum organization on the study progress. A hypothesis was formulated and tested about specific curriculum characteristics that can affect the academic progress and performance of the students. These characteristics included the spread of study activities over the years, the instruction and teaching characteristics, the examination characteristics, and the overall coherence of the program. The study highlighted that study progress is better in coherent programs comprising a relatively small number of theoretical courses rather than in a scattered program that comprises larger number of different courses. Also, the study highlighted that higher number of theoretical courses result in poor study progress of the students.

In a typical curriculum, courses are interlinked to some previous and following (pre-requisite) courses, or co-linked to some courses in the same semester (co-requisite). In the case of engineering study plans, the high degree of technical interdependence of course contents and the pre-and-co-requisite issues tend to complicate the smooth progression of students from one semester to another. These issues arise as a natural phenomenon since the engineering courses are hierarchical and sequential in nature. Probable delay in graduation may occur if a student fails a pre-requisite course that controls many other courses in the subsequent semesters. All over the world, engineering curricula are being subjected to revision and modifications in order to meet the pressing emerging issues such as strong scientific foundation, adequate social science requirements, strong exposure to ethics, good communications skills, enhanced technical communications, strong team spirit, and distance learning (Meyer \& Jacobs, 2000; Krizan, 2000; Hubka, 2000). However, little attention is paid to the flexibility and the interlinking between the courses in the resulting study plans. This has resulted in development of study plans that pose difficulties even to good students in terms of ease of progression in the study program.

Recently, there have been some attempts to revise engineering undergraduate curriculum to make engineering disciplines more capable of attracting and retaining students and to ease the severity of interlinking of courses in the curriculum. For example, in a project called "Deconstructing Engineering Education Programs", an attempt was made to offer greater flexibility to the students by reducing and reordering the prerequisite structure of the mechanical engineering undergraduate curriculum (BuschVishniac, et al., 2011). Eder \& Hubka (2005) suggested that a curriculum or study plan should meet the educational objectives in a previously-articulated means through the choice of the educational material and the teaching constraints and regulations. A study plan, therefore, should define the topics or subject matter to be presented, their volume in terms of scope and detail, and the sequence in which they should be instructed. It should also define relationships among the topic regions and demonstrate to the students how these topics relate to one another. Explaining the importance of flexibility and adaptability in engineering education, Krasniewski (2003) suggested that study plans should be flexible and should provide freedom to the students in designing his/her individual program of study by avoiding restrictions due to an excessive number of compulsory or interlinked courses. More recently, Alpay (2013) highlighted the importance of curricula flexibility and breadth in attracting engineering students. Other researchers proposed a novel approach for designing flexible curricula (Vodovozov \& Raud, 2011; Vodovozov \& Raud, 2012). The study suggests the use of a new tool called an educational thesaurus in order to improve the quality and effectiveness of the learning process. An extreme care is, therefore, required while developing curricula in engineering and science-discipline majors. A special consideration is required to avoid multiple prerequisites, high degree of interconnectivity, and hierarchical structure of the courses. Any curriculum stressed by pre-and-co-requisites will render that study plan rigid and will complicate smooth progression of the students.

The aim of this study is to apply the quantitative indicator of flexibility, developed by Darwish (2011), to several engineering curricula in three of the leading universities in United Arab Emirates. Strong ties of preand-co-requisites have been highlighted and the degree of rigidity in the selected engineering curricula has been calculated using a quantitative (relaxation) index. Finally, the stressed course in each curriculum have been highlighted and improvements in the structure of the selected curricula have been suggested in order to facilitate smooth students' progression. 


\section{METHODOLOGY}

The quantitative indicator of curriculum flexibility developed by Darwish (2011) has been applied in this study. The prediction of curriculum flexibility is based on the calculation of two distinct indices for each course in a study plan. These two indices have been named relaxation index (RI) and in-tandem chain index or simply chain index $(C I)$ and are developed based entirely on logic. A description of these quantitative indicators of curriculum flexibility is presented in this section.

\section{Relaxation Index (RI)}

In a typical curriculum, a highly stressed course is the one which is linked or connected to many pre-andco-requisites in the current or previous semesters. On the other hand, a stand-alone course with no connections with any other course in the curriculum is considered as a totally relaxed course. In fact, each course in a certain semester can be considered as a nodal point that is connected to former (pre-requisite) courses in the previous semesters, subsequent (post-requisite) courses in the upcoming semesters, or current (co-requisite) courses in the same semester. These connections can be assigned numerical values between zero and one, called connection strength (CS), based entirely on logical argument. Table 1 summarizes the logical values of $C S$ for different connection scenarios.

The relaxation index $(R I)$ for a given course in a certain study plan is calculated from the connection strength values as follows:

$$
R I=1-\frac{\sum_{k=1}^{k=N C} C S_{k}}{N C S}
$$

Where $N C$ is the number of connections associated the course under consideration, $C S_{k}$ is the value of the CS for connection k, and NCS is the total number of courses in the semester of the course under consideration. The value of $R I$ will be 1 for a standalone course that is not connected to any other course in the same or other semesters. On the other hand, a totally stressed course will have RI value of zero. The number of connections with other courses in directly adjacent semesters for a totally stressed course will be equal to the number of courses in the semester under consideration. In addition, the value of RI can also be negative. This is true for an overstressed course that has higher number of connections than the number of courses in the semester under consideration.

An example for the calculation of $R I$ is presented in Table 2 by creating a network structure for the pre-, post-, and co-requisites. In Table 2, the first course in the third semester is considered as a node and numerical values of $C S$ are assigned based on the connection scenarios in Table 1. The course under consideration has two pre-requisites. The first pre-requisite occurs in the second semester $(C S=1)$. While the second pre-requisite occurs in the first semester $(C S=0.5)$. In addition, the course itself is a pre-requisite for two other courses, one course in the subsequent semester $(C S=1)$ and another course in the sixth semester $(C S=0)$. Also, the course is a co-requisite for another course in the same semester $(C S=0.5)$. Using Eq. (1), the numerical value of relaxation index $(R I)$ for this course is:

$$
R I=1-\frac{\sum_{k=1}^{k=N C} C S_{k}}{N C S}=1-\frac{1+0.5+1+0+0.5}{5}=0.4
$$

\section{Chain Index (CI)}

The course relaxation index $(R I)$ does not indicate or quantify the contribution of a certain course to the overall stiffness of a curriculum or study plan. In most curriculums, some of the courses stand in long in-

Table 1. Logical Connection Strength (CS) values

\begin{tabular}{l} 
Connection Scenario \\
\hline A connection between a course standing as a pre-requisite and a subsequent course directly in the next semester \\
A floating (standing alone) course that is not connected with any previous, current or subsequent courses in the \\
curriculum or a connection between courses occurring after or before three semesters or more \\
A course connected to other courses in the same semester as co-requisites \\
\hline
\end{tabular}


Table 2. A hypothetical example of relaxation index (RI) calculation with the node at the first course in Semester 3 (Circles represent courses, solid arrows represent pre-requisites and post-requisites, and dashed two-directional arrows represent co-requisites)

\begin{tabular}{cccccccc}
\hline Semester 1 & Semester 2 & Semester 3 & Semester 4 & Semester 5 & Semester 6 & Semester 7 & Semester 8 \\
\hline 0 & 0 & 0 & 0 & 0 & 0 & 0 & 0 \\
0 & 0 & 0 & 0 & 0 & 0 & 0 & 0 \\
0 & 0 & 0 & 0 & 0 & 0 & 0 & 0 \\
0 & 0 & 0 & 0 & 0 & 0 & 0 & 0 \\
0 & 0 & 0 & 0 & 0 & 0 & 0 & 0 \\
\hline
\end{tabular}

tandem semester-to-semester chains of pre-and-post-requisites. This phenomenon poses a serious obstacle for the students and may potentially delay the completion of degree requirements if a student fails one of these courses occurring in long in-tandem chains.

In general, a course that acts as a pre-requisite for another course in the next semester and has only one pre-requisite directly in the previous semester is occurring in an in-tandem semester-to-semester chain length of 2. The in-tandem semester-to-semester chains of length of 2 are already taken into consideration in the aforementioned course relaxation index $(R I)$. However, when the in-tandem semester-to-semester chain length becomes three or more, the chain length needs to be taken into account (Darwish, 2011). The chain index $(C I)$ for a certain chain involving a certain course is logically defined logically by the following expression:

$$
C l=1-\frac{\text { Chain Length }-2}{N S-2}=\frac{N S-\text { Chain Length }}{N S-2}
$$

Where NS is the number of semesters in the study plan. In case if a pre-requisite chain extends over all semesters in the study plan, which is unlikely to occur, the $C I$ value would be zero. On the other hand, the value of $C I$ would be 1 for a chain length of 2 .

\section{Net Relaxation Index (NRI)}

Using the relaxation index $(R I)$ and the chain index $(C I)$, the net course relaxation index (NRI) for stressed courses occurring in long in-tandem semester-to-semester chains is computed as follows:

$$
N R I=R I \times \prod_{k=1}^{k=N C h} C I_{k}
$$

Where $C I_{k}$ is the index of chain " $k$ " for the stressed course under consideration, $N C h$ is the number of chains involving the course, and the symbol $\prod$ signifies multiplication. However, in this study, the multiplication term is assumed to be dominated by the longest chain and hence only one term, corresponding to the longest chain, has been used in NRI computations.

\section{Net Semester Relaxation Index (SRI)}

The net semester relaxation index (SRI) for a certain semester in the study plan is simply the average of relaxation indices for all the courses occurring in that semester as shown below:

$$
S R I=\frac{\sum_{k=1}^{N C S}(N R I)_{k}}{N C S}
$$

Where NCS represents the total number of courses in semester under consideration.

\section{Overall Curriculum Relaxation Index (CRI)}

The overall curriculum relaxation index $(C R I)$ is computed as the average of all courses' relaxation indices over the whole study plan. The equation is shown below:

$$
C R I=\frac{\sum_{k=1}^{N S}(N R I)_{k} \times(S R I)_{k}}{N C}
$$

Where $N C$ represents the total number of courses in the overall study plan. 


\section{RESULTS \& DISCUSSION}

In this section, we discuss and analyze the implication of the above quantitative measures to the study engineering curricula at four of the leading universities in the UAE that is the American University of Sharjah (AUS), the University of Sharjah (UOS), United Arab Emirates University (UAEU), and the Petroleum Institute (PI). Table 3 provides a summary of the selected engineering curricula from each university, including the total number of courses and the total number of credit hours.

Using the study plans of the selected engineering programs, the net course relaxation index (NRI) for each course was calculated using Eqs. (1-4). The semester relaxation index (SRI) was calculated using Eq. (5) and finally, Eq. (6) was used to predict the overall curriculum relaxation index (CRI). As an example, Table 4 shows the study plan for the Chemical Engineering Program at the American University of Sharjah (Darwish, 2011). Each course in the study plan was considered as a node and the NRI for each course was determined as shown in parentheses in Table 4. Similar tables were generated to calculate the relaxation indices for the engineering curricula mentioned in Table 3.

In a healthy structured study plan, it is expected that semesters relaxation index improves (increases) steadily from the first semester onwards. However, this trend was not observed in any study plan offered by the four universities. In case of AUS, Figure 1 depicts a very low value of SRI in semester 4 of the chemical engineering program. It is, therefore, advisable to relax some of the pre-requisites in this semester. The courses in the civil engineering curriculum at AUS were found to be stressed in semesters 3 and 4 (second year). A special consideration is required to relax the pre-requisites in the mechanical engineering program at AUS that exhibited low SRI values in both the second and the third year of the study plan. The overall curriculum relaxation index $(C R I)$ for the civil, chemical, and mechanical engineering programs at AUS were computed to be $82.0 \%, 70.0 \%$, and $70.0 \%$, respectively.

Figure 2 shows the SRI values for the engineering curricula at UOS. The electrical and electronics engineering curriculum at UOS exhibit extremely low values of SRI in the second year of the study plan. The mechanical engineering program, on the other hand, showed low SRI values in the second, third, and the fourth semester. The civil \& environmental engineering program at UOS was found to be highly stressed by pre-requisites in the fourth and fifth semester. The overall curriculum relaxation index $(C R I)$ for the civil \& environmental, electrical \& electronics, and mechanical engineering programs at UOS were computed to be $79.4 \%, 79.3 \%$, and $81.1 \%$, respectively. Compared to AUS, the engineering curricula at UOS were found to be slightly more relaxed.

Table 3. Summary of selected engineering curricula from universities in the UAE

\begin{tabular}{llcccc}
\hline University & Program/Major & $\begin{array}{c}\text { Number of } \\
\text { Semesters }\end{array}$ & $\begin{array}{c}\text { Number of } \\
\text { Courses }\end{array}$ & $\begin{array}{c}\text { Credit } \\
\text { Hours }\end{array}$ & Reference \\
\hline $\begin{array}{l}\text { The American University } \\
\text { of Sharjah (AUS) }\end{array}$ & Civil Engineering & 8 & 50 & 140 & (AUS, 2015) \\
& Chemical Engineering & 8 & 51 & 140 & (AUS, 2015) \\
& Mechanical Engineering & 8 & 51 & 140 & (AUS, 2015) \\
\hline $\begin{array}{l}\text { The University of Sharjah } \\
\text { (UOS) }\end{array}$ & Civil \& Environmental Engineering & 8 & 50 & 135 & (UOS, 2015a) \\
& Electrical \& Electronics & 8 & 55 & 138 & (UOS, 2015b) \\
& Engineering & & & & \\
& Mechanical Engineering & 8 & 50 & 132 & (UOS, 2015c) \\
\hline The Petroleum Institute & Electrical Engineering & 8 & 40 & 131 & (PI, 2014a) \\
PI) & Chemical Engineering & 8 & 40 & 132 & (PI, 2014b) \\
& Mechanical Engineering & 8 & 44 & 135 & (PI, 2014c) \\
\hline United Arab Emirates & Chemical Engineering & 10 & 49 & 147 & (UAEU, 2014a) \\
University (UAEU) & Civil \& Environmental Engineering & 10 & 46 & 147 & (UAEU, 2014b) \\
& Mechanical Engineering & 10 & 50 & 147 & (UAEU, 2014c) \\
\hline
\end{tabular}




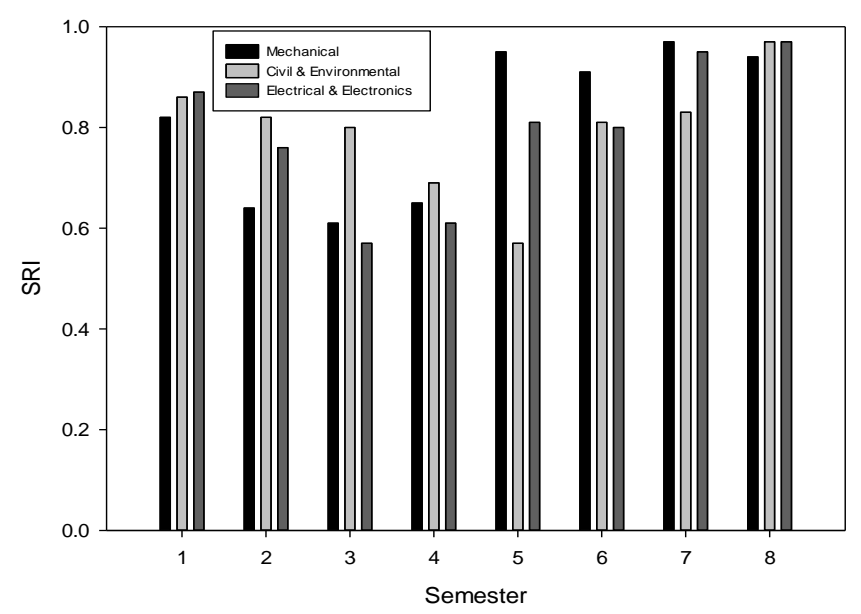

Figure 2. Relaxation index for each semester in the study plan for the Electrical \& Electronics, Civil \& Environmental, \& Mechanical Engineering at the University of Sharjah (UOS)

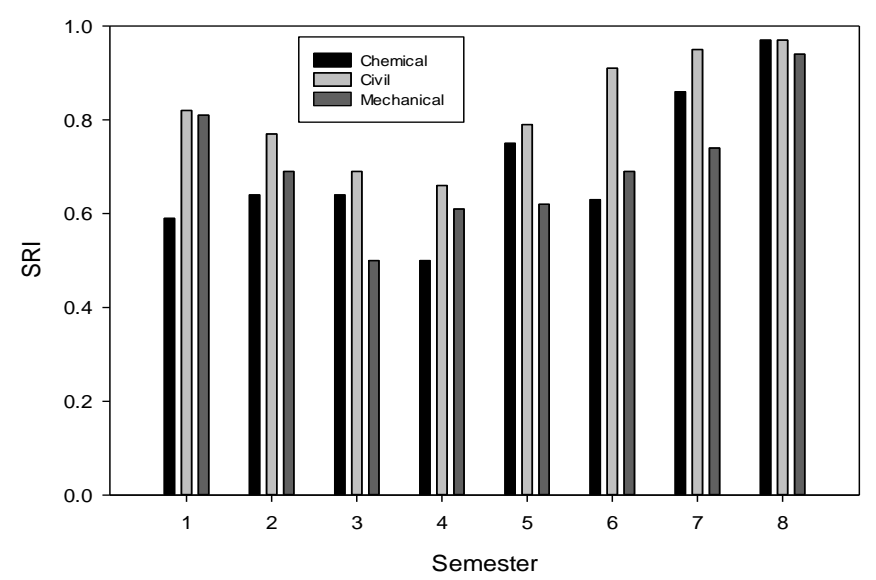

Figure 1. Relaxation index for each semester in the study plan for the Chemical, Civil, \& Mechanical Engineering at the American University of Sharjah (AUS)

Table 4. The study plan for the Chemical Engineering Department at the American University of Sharjah with pre-requisites (solid arrows), co-requisites (dashed two-directional arrows), course relaxation indices (numbers in parentheses), and semester relaxation indices (numbers is the last row) (Darwish, 2011)

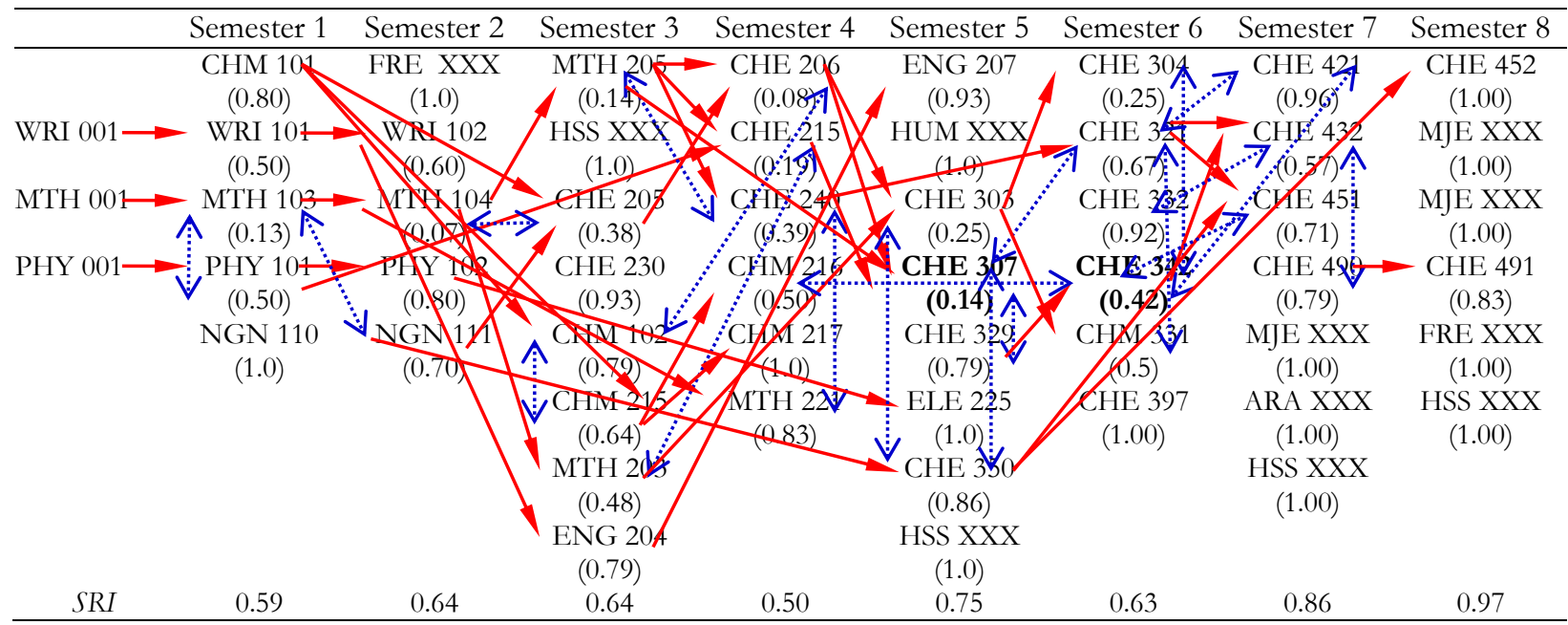


The SRI values for the selected engineering curricula at PI are shown in Figure 3. All the curricula at PI were found to be highly stressed throughout semesters 2 to 6 . Much of these pre-requisite stresses were particularly focused in the second year and in the later part of the first year of the study plans. The overall curriculum relaxation index $(C R I)$ for the chemical, electrical, and mechanical engineering programs at PI were found to be $62.3 \%, 74.8 \%$, and $75.5 \%$, respectively.

The mechanical engineering program at UAEU showed a steady increase in SRI values from the first semester onwards with low SRI value only in the fourth semester (Figure 4). Similarly, a steady increase in $S R I$ values was also observed for the civil \& environmental engineering program. However, the eight semester has a zero SRI value since the only course in this semester, Industrial Training (CIVL 495), acts a pre-requisite for other courses in the subsequent (ninth) semester. Similar case was observed for the chemical engineering program at UAEU. The eight semester, corresponding to Industrial Training (CHME 495), has a zero $S R I$ value. In addition, the courses in the second and fourth semesters were found to be stressed. The overall curriculum relaxation index $(C R I)$ for the civil \& environmental, mechanical, and chemical engineering programs at UAEU were found to be $91.4 \%, 86.7 \%$, and $79.1 \%$, respectively.

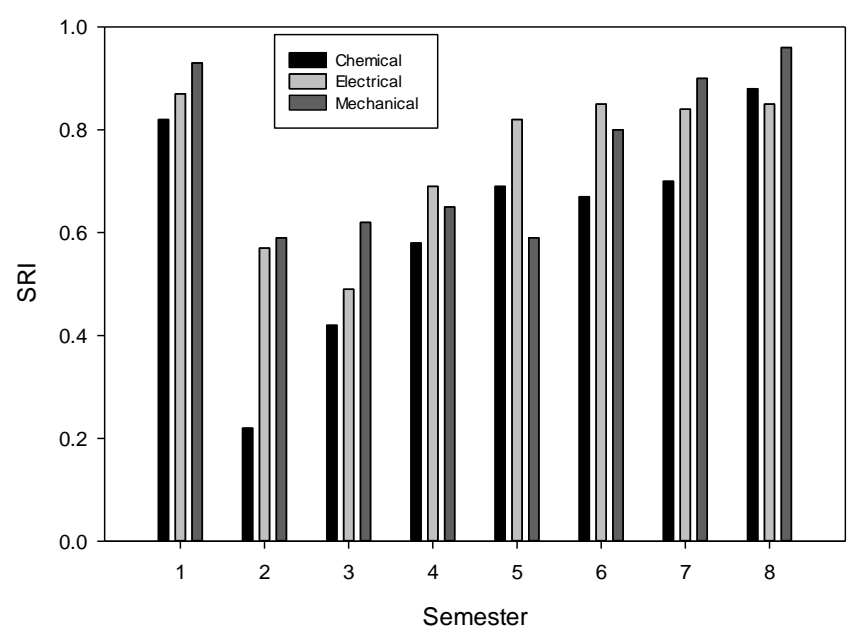

Figure 3. Relaxation index for each semester in the study plan for the Chemical, Electrical, \& Mechanical Engineering at the Petroleum Institute (PI)

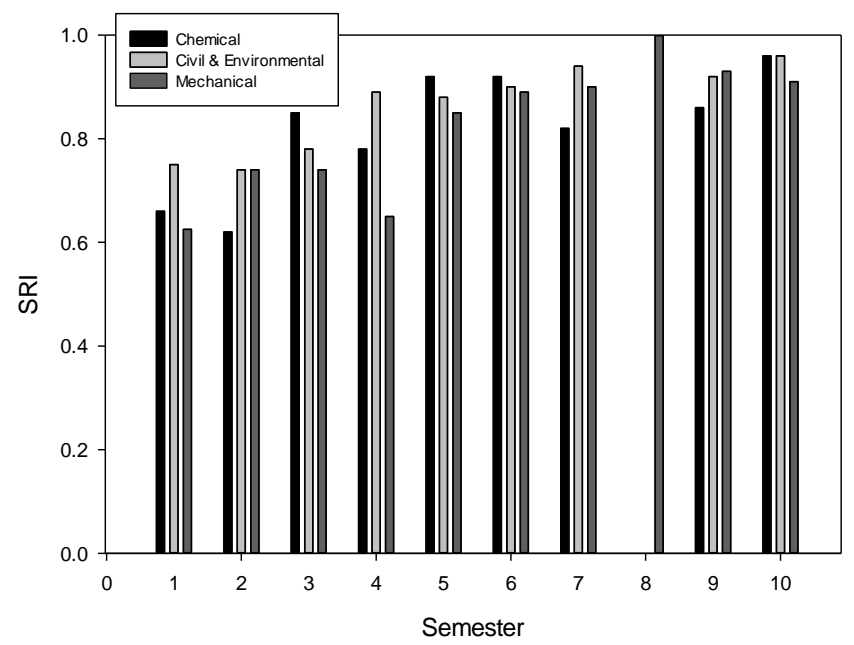

Figure 4. Relaxation index for each semester in the study plan for the Chemical, Civil \& Environmental, \& Mechanical Engineering at the United Arab Emirates University (UAEU)

In short, the chemical engineering study plan at PI is the least flexible while the civil \& environmental study plan at UAEU is the most flexible among all the study plans considered in this study. Each selected university is suggested to give immediate attendance towards relaxing the strong pre-and-co-requisite ties connecting the stressed courses $(N R I<0.5)$ listed in Table 5 . These courses are, in fact, the bottlenecks for 
students' progression from one semester to another. In order to facilitate smooth progression of students from one semester to another, strong ties of the pre-and-co-requisite must be avoided and the SRI should improve (increase) steadily from the first semester onwards. Relaxation of strong pre-and-co-requisite ties requires expertise in each curricula. Although relaxation of strong pre-and-co-requisite ties will enhance the curriculum flexibility, important curriculum objectives such as efficient achievement of course and program learning outcomes may be compromised. For the courses listed in Table 5, any changes or adjustments in the pre-and-co-requisites must be made taking into account the course and program learning outcomes.

The proposed metric has been successfully applied to different engineering curricula in the United Arab Emirates. Although curriculum flexibility can be quantified, the metric has certain limitations. The connection strength $(C S)$ value is based on logic and can assume any value between zero and one. For the same curriculum, this may result in different $S R I$ and $C R I$ values depending on the $C S$ values assumed by the metric user. In addition, only pre-and-co-requisite ties have been considered as a factor affecting smooth student progression. Other factors such as course content and level of difficulty have not been embedded within the metric. Furthermore, the metric is only applicable to American-based curricula and may have

Table 5. Courses that require relaxation of strong pre-and-co-requisite ties in the studied engineering curricula $(N R I<0.5)$

\begin{tabular}{lll}
\hline University & Program/Major & Stressed Course Title (Course Code) \\
$\begin{array}{l}\text { The American } \\
\begin{array}{l}\text { University of Sharjah } \\
\text { (AUS) }\end{array}\end{array}$ & $\begin{array}{l}\text { Civil Engineering } \\
\text { of Materials (CVE 223), Geotechnical Engineering Principles (CVE 331) }\end{array}$ \\
\cline { 2 - 3 } & Chemical Engineering & Calculus I (MTH 103), Calculus II (MTH 104), Differential Equations (MTH
\end{tabular}
2015), Principles of Chemical Engineering I (CHE 205), Calculus III (MTH 203), Principles of Chemical Engineering II (CHE 206), Fluid Flow (CHE 215), Computer Methods in Chemical Engineering (CHE 240), Chemical Engineering Thermodynamics I (CHE 303), Heat Transfer (CHE 307), Chemical Engineering Thermodynamics II (CHE 304), Separation Processes (CHE 342)

Mechanical Engineering Calculus II (MTH 104), Physics II (PHY 102), Thermodynamics I (MCE 241), Statics (MCE 220), Electric Circuits and Devices (ELE 225), Dynamics (MCE 222), Mechanics of Materials (MCE 223), Fluid Mechanics (MCE 240), Engineering Measurements (MCE 311), Mechanical Design I (MCE 321), Computer Applications in Mechanical Engineering II (MCE 326L), Control Systems (MCE 410)

The University of Civil \& Environmental Statics (0401201), Surveying (0401222), Mechanics of Materials (0401202), Sharjah (UOS) Engineering Dynamics (0401243), Fluid Mechanics (0401343), Geotechnical Engineering (0401351), Transportation Engineering (0401321), Reinforced Concrete Design 1 (0401314), Senior Design Project 1 (0401498)

Electrical \& Electronics Physics II Lab (1430118), Digital Logic Design (0403201), Circuit Analysis I Engineering (0402202), Circuit Analysis I Lab (0402203), Signals and Systems (0402240)

Mechanical Engineering Statics (0401201), Calculus II for Eng. (1440161), Differential Equations for Eng. (1440261), Dynamics (0401243), Kinematics (0408220), Mechanics of Materials (0401202)

The Petroleum $\quad$ Electrical Engineering $\quad$ Calculus II (MATH 161), Communication II (COMM 151), Electric Circuits I Institute (PI) (ELEG 205), Differential Equations (MATH 261)

Chemical Engineering Chemistry II (CHEM 102), Physics I: Mechanics (PHYS 191), Calculus II (MATH 161), Communication II (COMM 151), Physics II: Electromagnetism (PHYS 241), Calculus II (MATH 212), Engineering Practices I (STPS 201), Principles of Chemical Engineering (CHEG 200), Differential Equations (MATH 261), Fluid Mechanics (CHEG 301), Designed Experimentation (CHEG 331), Heat Transfer (CHEG 361), Mass Transfer (CHEG 351), Design Project I (CHEG 490)

Mechanical Engineering $\quad$ Physics I: Mechanics (PHYS 191), Communication II (COMM 151), Engineering Statics (MEEG 201), Strategies for Team Based Eng. Problem Solving I (STPS 201), Differential Equations (MATH 261), Fluid Mechanics (MEEG 354), Engineering MATLAB (MEEG 221), Systems Dynamics \& Control (MEEG 384)

United Arab Emirates Chemical Engineering $\quad$ English Language (2100), Mathematics (3100), Calculus I for Engineering (MATH University (UAEU) 1110), Physics I for Engineering (PHYS 1110), General Chemistry I (CHEM 111), Calculus II for Engineering (MATH 1120), Physical Chemistry I (CHEM 251), General Chemistry II (CHEM 112), Industrial Training (CHME 495)

Civil \& Environmental Mathematics (3100), Calculus I for Engineering (MATH 1110), Calculus II for Engineering Engineering (MATH 1120), Industrial Training (CIVL 495)

Mechanical Engineering English Language (2100), Mathematics (3100), Calculus I for Engineering (MATH 1110), Physics I for Engineering (PHYS 1110), Calculus II for Engineering (MATH 1120), Statics (GENG 240), Mechanics of Materials (GENG 305) 
limited applications for curricula based on yearly modules or qualifications such as those in most universities in the United Kingdom.

\section{CONCLUSION}

In this study, a quantitative index (relaxation index, $R I$ ) was used to reflect the degree of interconnectivity between courses in engineering curricula at the American University of Sharjah, the University of Sharjah, United Arab Emirates University (UAEU), and the Petroleum Institute. The values of RI were used to determine the overall semester and the overall study plan relaxation index. The chemical engineering curriculum at PI was found to be the least flexible while the civil \& environmental curriculum at UAEU was found to be the most flexible among all the study plans considered in this study. It is strongly recommended to relax some of the strong ties of pre-requisites prevailing in the semesters with low values of $S R I$ for each study plan.

\section{REFERENCES}

Alpay, E., 2013. Student attraction to engineering through flexibility and breadth in the curriculum. European Journal of Engineering Education, 38(1), pp. 58-69.

AUS, 2015. Undergraduate Catalog - American University of Sharjab. [Online] Available at: http://www.aus.edu/downloads/file/1416/undergraduate_catalog.

[Accessed 26 August 2015].

Busch-Vishniac, I. et al., 2011. Deconstructing Engineering Education Programs: The DEEP Project to Reform the Mechanical Engineering Curriculum. European Journal of Engineering Education, 36(3), pp. 269-283.

Crombag, H. F., Gaff, J. G. \& Chang, T. M., 1975. Study behavior and academic performance. Journal for education research, 1(1), pp. 3-14.

Darwish, N. A., 2011. Development of a new quantitative indicator of flexibility in undergraduate engineering curricula,. Madrid, the 4th International Conference of Education, Research and Innovation.

Eder, E. W. \& Hubka, V., 2005. Curriculum, Pedagogics and Didactics for Design Education. Journal of Engineering Design, 16(1), pp. 45-61.

Hubka, V., 2000. Design Education in an Engineering Curriculum. Pilsen, International Workshop EED- Education for Engineering Design.

Hulst, M. v. d. \& Jansen, E., 2002. Effects of curriculum organization on study progress in engineering studies. Higher Education, 43(4), pp. 489-506.

Hulst, M. v. d. \& Jansen, E., 2002. Effects of Curriculum Organization on Study Progress in Engineering Studies. Higher Education, 43, pp. 489-506.

Jansen, E. P. W. A., 1993. Curriculum Organization and Study Progress. In: T. H. Joostens, G. W. H. Heijnen \& A. J. Heevel, eds. Doability of Curricula. The Netherlands: Swets and Zeilinger, pp. 135-149.

Johnson, J. L. \& Bloom, M., 1995. An analysis of the contribution of the five factors of personality to variance in academic procrastination. Personality and Individual Differences, 18(1), pp. 127-133.

Krasniewski, A., 2003. Promoting Mobility and Interdisciplinary Education through Three-Cycle Open Structure of Studies and Flexible Curricula. Porto, SEFI Annual Conference.

Krizan, B., 2000. Possible Improvements in the Curriculum for Education in Mechanical Engineering. Pilsen, International Workshop EED- Education for Engineering Design.

Macan, T. H., 1994. Time management: test of a process model. Journal of Applied Psychology, 79(3), pp. 381-391.

Meyer, M. D. \& Jacobs, L. J., 2000. A Civil Engineering Curriculum for the Future: The Georgia Tech Case. Journal of Professional Issues in Engineering Education and Practice, 126(2), pp. 74-78.

Milgram, N. A., Dangour, W. \& Ravi, A., 1992. Situational and personal determinants of academic procrastination. The Journal of General Psychology, 119(2), pp. 123-133.

Milgram, N., Marshevsky, S. \& Sadeh, C., 1995. Correlates of academic procrastination: discomfort, task aversiveness and task capability. The Journal of Psychology, 129(2), pp. 145-155.

Nonis, S. A., Hudson, G. I., Logan, L. B. \& Ford, C. W., 1998. Influence of perceived control over time on college students' stress and stress-related outcomes. Research in Higher Education, 39(5), pp. 587-605.

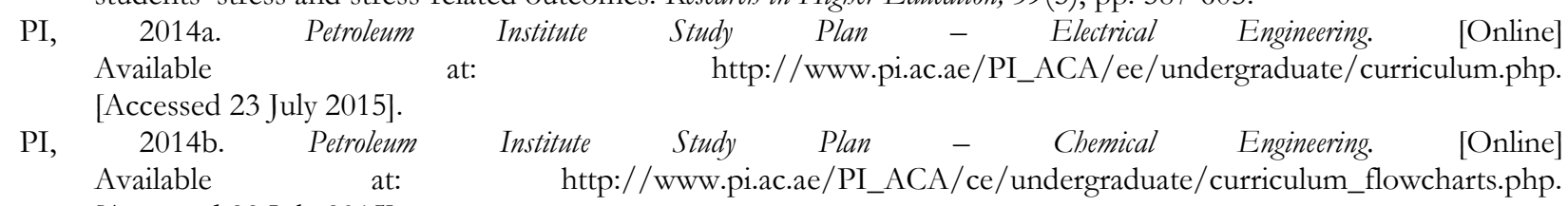
[Accessed 23 July 2015]. 
PI, 2014c. Petroleum Institute Study Plan - Mechanical Engineering. [Online] Available at: http://www.pi.ac.ae/PI_ACA/me/undergraduate/curriculum.php. [Accessed 23 July 2015].

Schouwenburg, H. C., 1992. Procrastinators and fear of failure: an exploration of reasons for procrastination. European Journal of Personality, 6, pp. 225-236.

Senécal, C., Koestner, R. \& Vallerand, R. J., 1995. Self-regulation and academic procrastination. The Journal of Social Psychology, 135(5), pp. 607-619.

UAEU, 2014a. Study Plan - Chemical Engineering, Al-Ain: UAE University.

UAEU, 2014b. Study Plan - Civil \& Environmental Engineering, Al-Ain: UAE University.

UAEU, 2014c. Study Plan - Mechanical Engineering, Al-Ain: UAE University.

UOS, 2015a. Univerity of Sharjah Study Plan - Civil \& Environmental Engineering. [Online] Available http://www.sharjah.ac.ae/en/academics/colleges/eng/dept/ced/dp/cveb/Documents/Studyplan\%2020122013.pdf [Accessed 26 August 2015].

UOS, 2015b. University of Sharjah Study Plan - Electrical \& Electronics Engineering. [Online] Available at: http://www.sharjah.ac.ae/en/about/agc/publications/Documents/5-Engineering.pdf\#sp-ecep [Accessed 28 August 2015].

UOS, 2015c. University of Sharjah Study Plan - Mechanical Engineering. [Online] Available http://www.sharjah.ac.ae/en/academics/colleges/eng/dept/MechanicalEngineering/Documents/ME\%20Flowc hart_V3.pdf [Accessed 28 August 2015].

Vaughan, C. \& Carlson, C., 1992. Teaching and Learning One-Course- at-a-Time. Innovative Higher Education, 16(4), pp. 263-276.

Vodovozov, V. \& Raud, Z., 2011. Curricula scheduling using educational thesaurus. Cairo, The World Congress on Computer Science and Information Technology (WCSIT 2011).

Vodovozov, V. \& Raud, Z., 2012. Flexible curricula based on educational thesaurus. Napoli, International Conference on Computers and Advanced Technology in Education (CATE 2012). 